\title{
Marechal Lott, ilustre desconocido
}

AUTOR

\section{Elisa Tavares}

Duarte*

elisa.duarte@usal.es

* Doctoranda en Estudios Latinoamericanos por la Universidad de Salamanca

\author{
Marechal Lott, ilustre desconhecido
}

Marechal Lott, illustrious unknown

\author{
GUILHERME Carloni, Karla \\ Marechal Lott. A opção das esquerdas. Uma biografia política. \\ Río de Janeiro: Garamond, 2014 \\ 312 páginas. ISBN: 9788576173830
}

Creo que la primera apreciación que todo lector hace después de leer un libro es sobre el disfrute de la lectura. Obviamente, se trata de una apreciación subjetiva. En el caso del libro Marechal Lott, de Karla Guilherme Carloni, no lo sería si no fuera porque en su "Prefacio", el profesor e historiador Daniel Aarão Reis, así también lo valora. Además de presentar un leguaje claro - eso sí, la obra está escrita en portugués-, preciso, que facilita la comprensión del enredo por parte de los menos familiarizados con las obras históricas, no renuncia en absoluto al rigor metodológico que tanto nos complace a los historiadores. Y eso son dos grandes virtudes para una obra que trata de un tema tan espinoso, como la biografía de un personaje, uno de los grandes protagonistas de los principales - y más aterradores - hechos de la historia de la República brasileña, pero voluntariamente - como lo demuestra la autora - olvidado y, actualmente, prácticamente desconocido para la sociedad brasileña.

La obra es el resultado de años de investigación, que primeramente dieron origen a su tesis doctoral, titulada Marechal Henrique Teixeira Lott: a opção das esquerdas, leída en 2010, en el programa de postgrado en Historia de la Universidad Federal Fluminense (Niterói, Río de Janeiro, Brasil). El libro que se publica el año pasado [2014] pone de manifiesto en su introducción, cuál es su objetivo fundamental: "Como compreender a grande projeção pública e o esquecimento social de um militar que em um passado não muito distante cativou de maneira expressiva soldados e trabalhadores?" (Guilherme, 2014: 15).

Veamos el camino que hace la autora. El protagonista del libro se llamaba Henrique Baptista Duffles Teixeita Lott; nacido a finales del siglo XIX, vino a fallecer en 1984, sin haber llegado a ver el final de la Dictadura - si no totalmente militar, como lo cuestiona la historiografía brasileña, ya que contó con importantes apoyos del sector civil de la sociedad. Por las fechas de nacimiento y muerte, sabemos que su vida trascurrió a lo largo de conturbados años de la política brasileña: nacía cinco años después del "nacimiento" de la República en Brasil; luego, entre otros, vivió la "República Velha", la "Revolução de 30", “Estado Novo", "Golpe Militar”; todo esto, de los grandes 
hechos de la historia, testigo también, como lo señala la autora, de importantes cambios en el Ejército brasileño y de su participación en la política y en el gobierno del país.

La obra está estructurada en seis capítulos. El primero de ellos dedicado a centrar la biografía de Lott en el campo de la Memoria. Luego, siguen los capítulos que tratan de los principales momentos de su vida, aquellos en los que tuvo mayor protagonismo en el escenario brasileño: en el contragolpe de 1955, que le garantizaba a Juscelino Kubitschk la asunción de la presidencia, ministro de Guerra durante dos gobiernos y, luego candidato a la presidencia en 1960. A partir de ahí, con la derrota en las urnas, Lott se retira del primer plano de la política, aunque sin abandonarla totalmente. Es así que en un periodo muy corto de tiempo, en 1961 y 1964, el mariscal fue detenido dos veces, por manifestarse públicamente, primero contra el veto de los militares a la subida al poder del entonces vice-presidente Jânio Quadros, y luego, la víspera de estallar el golpe militar, denunciándolo públicamente en la prensa nacional.

Finalmente, el último capítulo, brinda al lector un interesante abordaje (presente también aquí y allí a lo largo de la obra), acerca de las dos generaciones que siguen a Lott en la vida política, pero con destinos menos afortunados: su hija, Edna Lott, que había sido diputada estadual por los partidos PTB y MDB, asesinada por los militares por haber denunciado el secuestro y tortura de su hijo, Nelson Luiz Lott de Moraes Costa, que aunque tenía formación y carrera militar, las abandona, ingresa en la Facultad de Historia de la Universidad Federal Fluminense, entrando después en la Aliança Libertadora Nacional y, con tan sólo veinte años de edad, fue detenido y permaneció en las dependencias de las Fuerzas Armadas brasileñas durante cuatro años, sufriendo toda clase de torturas y restricciones.

Esta es, básicamente, la estructura de la obra. No obstante, el hilo que conduce la narrativa no son los hechos, grandes pero lamentables, de la reciente historia de Brasil: el trabajo de la autora consistió en centrar la biografía de Lott en esos hechos, desarrollando todos los argumentos que contribuyeron para que, a día de hoy, sea un "ilustre desconocido" de la historia e historiografía brasileña. Los argumentos son varios pero que pueden ser resumidos (sin que se pueda prescindir de las reflexiones de la autora): el olvido del que se trata está presente en hechos - su entierro no contó con los honores militares debidos -, pero también lo está en la historiografía, en las producciones académicas más recientes. ¿Cómo entenderlo? Un personaje que gozó de tanta proyección política, habiendo ocupado puestos de gran importancia en el gobierno, prácticamente no existe en los libros de historia de Brasil.

A lo largo de los cinco años en los que estuvo en la primera fila de la política brasileña, el Marechal Lott se convirtió en el icono de la legalidad política, abrigando bajo su influencia a civiles y militares, los de más bajo rango - es cierto, y aquellos que defendían en Brasil un proyecto "nacionalista", identificado, entre otras cosas, con la industrialización sin la intervención del capital extranjero, la extensión de los derechos sociales de trabajo a los trabajadores del campo y la ampliación de los mismos a los trabajadores urbanos; etc., pero sobre todo, identificado como el "líder", el "héroe nacional", capaz de mantener y defender la democracia en años tan conturbados. Por otro lado, los sectores más conservadores de las Fuerzas Armadas, lo acusaban de usar el poder, mientras lo tuvo, en beneficio propio, y de "izquerdizar" las bases de las Fuerzas Armadas.

La opción metodológica empleada fue el abordaje del tema de la biografía a partir de la interacción del individuo con su época, su contexto y sociedad, utilizando un gran abanico de fuentes, prensa nacional, relatos de ex militares y obras biográficas producidas sobre Lott - desde las publicadas en su defensa, las que contribuyeron a la construcción del "mito" Lott -, hasta las que proclamaban que él era, en realidad, un falso militar. Incluso, uno de los poetas brasileños más conocidos en el escenario internacional, Manuel Bandeira, le dedica un poema que termina así: "É ouro sinistro, Ouro mareado: Mancha o Ministro, Mancha o Soldado" (Guilherme, 2014: 18). 
Más allá de verificar qué hay de veracidad en cada uno de los argumentos de los lados enfrentados, que en parte también corresponde a la operación histórica, la autora analiza la construcción del mito del "héroe nacional" durante los primeros años de la República, invocado en momentos de extrema dificultad y convulsión social como el defensor de la patria, el soldado que servía a la nación sin reservas por encima de su bien estar y, ¿por qué no?, de la propia vida. Lo cierto es que de haber gozado de tanta popularidad entre varios y amplios sectores de la sociedad brasileña, ¿cómo explicar la derrota en las urnas en 1960? Nuevamente, la autora recurre a la historiografía que señala el desgaste de JK y, consecuentemente, de su imagen como representante de un proyecto político continuista. Ahora bien, llegados los duros años de la dictadura, el mito del mariscal vuelve a ganar fuerza, ora por hechos inverosímiles atribuidos a él, ora condenado todavía de forma más dura por los segmentos conservadores de las Fuerzas Armadas, que entonces se hicieron con el poder.

Al final, la izquierda política brasileña le relega al ostracismo por, entre otros motivos, lo que representaba su vinculación con el Ejército, institución que debería haber protegido los derechos civiles de la sociedad como un todo, y el Ejército también así lo hace, pero en el intento de borrar de la memoria de la institución la existencia de oficiales entre sus filas que no estuvieron de acuerdo con las atrocidades que se llevaron a cabo en supuesta defensa de la democracia y de los buenos valores de la sociedad.

¿Qué queda actualmente del Marechal Lott? Como dice la autora, de los lugares de la memoria, una avenida en el barrio de Barra da Tijuca (Río de Janeiro) y tres escuelas. Igualmente, la academia sigue prestando poca atención a los militares nacionalistas. En sus palabras:

(...) a memória social sobre Lott e sobre os militares nacionalistas sofreu um amplo processo de esquecimento: foi renegada e deturpada pelos militares que em 1964 subiram ao poder; foi sobreposta pela trágica memória que a ditadura deixou como um dos seus legados e foi renegada por setores radicais da esquerda política que ainda consideram os setores reformistas desprovidos de valor real para a luta por uma sociedade mais justa" (Guilherme, 2014: 72).

En el emblemático texto sobre la Historia Política, "A História Política continua a ser a espinha dorsal da História?" publicado en el año de 1985, cuando el país recién le daba nuevamente la bienvenida a la democracia, el historiador francés Le Goff decía:

Há pior. Perante esta história mais a fazer que já feita, a história política tradicional é um cadáver que temos ainda de matar. É certo que uma gramática da história política é ainda - e sempre será - não somente útil mas mesmo necessária. A cronologia dos fatos políticos e as biografias dos homens políticos são indispensáveis. E, apesar dos progressos da democracia, a história política será sempre - não exclusivamente mas também - a história dos grandes. (Le Goff, 1994: 366).

Menos mal que, con suerte, contamos con aquellos que, aunque de forma tímida, nadan contra corriente.

\section{REFERÊNCIAS BIBLIOGRÁFICAS}

LE GOFF, Jacques. (1994). A história política cintinua a er a espinha dorsal da História?. Em: $O$ imaginário medieval. Lisboa: Estampa. 